\title{
Can $t$-BuOK be a good nucleophile? An ion-pairing answer. Cleavage of aryl ethers in their cationic iron complexes
}

\author{
Didier Astruc,* Laurent Djankovitch, and Jaime Ruiz Aranzaes \\ Molecular Nanosciences and Catalysis Group, LCOO, University Bordeaux I, \\ 351 Cours de La Libération, 33405 Talence, France \\ E-mail: d.astruc@lcoo.u-bordeaux1.fr
}

This Article is dedicated to our distinguished colleague Professor Armand Lattes

\begin{abstract}
$t$-BuOK reacts with cationic 18-electron $\mathrm{d}^{6} \mathrm{Fe}^{\mathrm{II}}$ complexes of aryl ethers ArOR as their $\mathrm{PF}_{6}{ }^{-}$salts to cleave the $\mathrm{C}-\mathrm{O}$ bond of the aryl ether, yielding $\mathrm{Fe}^{\mathrm{II}}$-hexahapto-phenolate complexes and the ethers $t$-BuOR, only in the presence of a salt, the best one being $\left[n-\mathrm{Bu}_{4} \mathrm{~N}\right]\left[\mathrm{PF}_{6}\right]$. Salt effects in THF result from either enhancement of nucleophilic reactivity of $t-\mathrm{BuO}^{-}$with a large cation or polarization of the aryl ether $\mathrm{C}-\mathrm{O}$ bond with a THF-insoluble salt such as $\mathrm{KBr}$ or $\mathrm{NaCl}$. This nucleophilic reaction of $t-\mathrm{BuO}^{-}$is of special interest for the 8-step synthesis of a triallyl phenol dendron obtained when the cleavage reaction of the complexes of aryl ethers is carried out in the presence of allyl bromide. During this reaction that is carried out without addition of a salt, it is the in situ formation of $\mathrm{KBr}$ during the three deprotonation-allylation sequences that further facilitates the crucial aryl ether cleavage at low temperature.
\end{abstract}

Keywords: Nucleophile, salt, potassium tert-butoxide, ion pair, complex, iron

\section{Introduction}

There has been considerable interest for the potential of anionic reagents to serve as bases and nucleophiles, ${ }^{1}$ and the role of ion-pairing, ${ }^{2}$ salts $^{3}$ and solvents ${ }^{4}$ has been shown to be essential. Potassium tert-butoxide has been found in the early 1960's to be an efficient base in DMSO, ${ }^{5}$ and the cation effect was recognized in these early days. ${ }^{6}$ Potassium tert-butoxide subsequently became a popular reagent that is used by everyone as a convenient base whose properties are seemingly well known. ${ }^{7}$ Its reactivity is not only that of a base, however, but it is multifold. For instance, its nucleophilic character can sometimes be expressed, as for instance in the presence of 18-crown-6 ether that segregates the potassium cation, providing an enhanced reactivity of the 
anion. ${ }^{8}$ Nevertheless, potassium tert-butoxide is little known as a nucleophile despite these seminal studies.

We have extensively used potassium tert-butoxide as a base together with an organic halide for the $\mathrm{CpFe}^{+}$-induced perfunctionnalization of polymethylbenzene. This set of reactions opened the route to stars and dendritic cores. For instance, in this way, hexamethylbenzene leads, with $\mathrm{R}=$ allyl, to either hexabutenylbenzene under ambient conditions (eq. 1$)^{9}$ or a dodecallyl arene in one pot, ${ }^{10}$ whereas mesitylene leads to nona-allylation also under ambient conditions in a one-pot reaction (eq.2). ${ }^{11}$
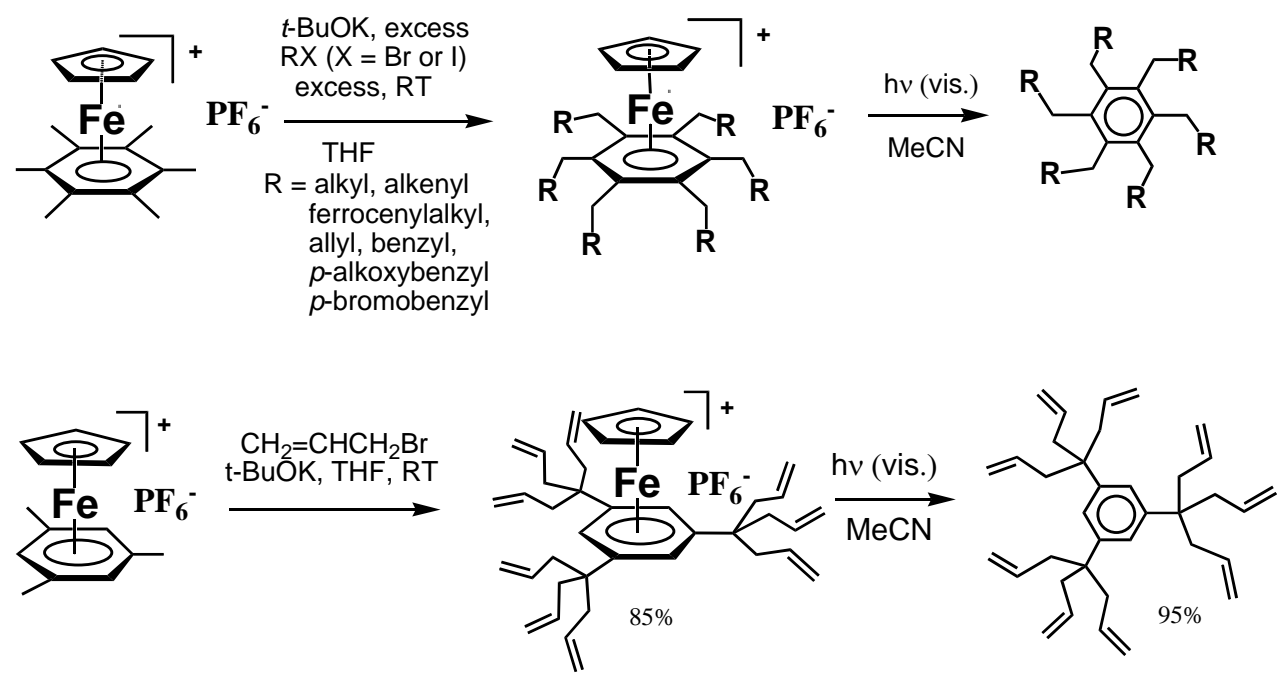

(eq. 2)

This latter reaction is the most commonly used one in our laboratory, as it is so easy and convenient to carry out on a large scale either using potassium tert-butoxide or potassium hydroxide. The nona-allyl aromatic obtained can be hydroborated ${ }^{9}$ or hydrosilylated $^{9,11}$ for further dendrimer construction using a phenoltriallyl brick (dendron A in Scheme 1$)^{12}$ that allows multiplying the number of branches by three at each dendritic generation. The largest dendrimers known have been built in this way and characterized until the $9^{\text {th }}$ generation bearing a theoretical number of $3^{11}$ branches, ${ }^{11}$ for the first time far beyond the de Gennes "dense-packing" limit ${ }^{13}$ (Scheme 1).

Thus, the production of the phenoltriallyl brick that is standard is crucial. It is carried out in a one-pot reaction from the cationic 18-electron $\mathrm{d}^{6} \mathrm{Fe}^{\mathrm{II}}$ complex of an aryl ether such as paraethoxytoluene and involves eight steps using potassium tert-butoxide and allyl bromide in THF, including the cleavage of the arylether complex (Scheme 2). Note the multiple roles of potassium tert-butoxide in this complex reaction: first as a base to deprotonate the iron complex in benzylic position, then for the cleavage of the aryl ether in the complex, then finally in the decomplexation reaction providing the desired free phenoltriallyl brick $\mathbf{A}$. 


\section{DIVERGENT CONSTRUCTION OF GIANT DENDRIMERS}

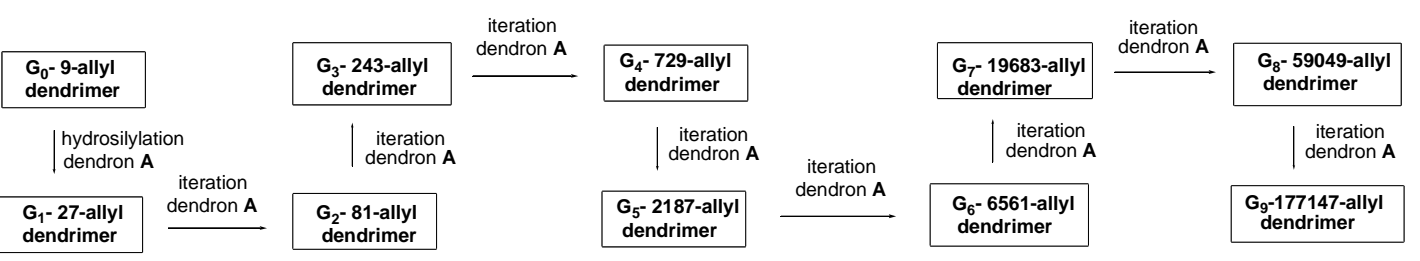
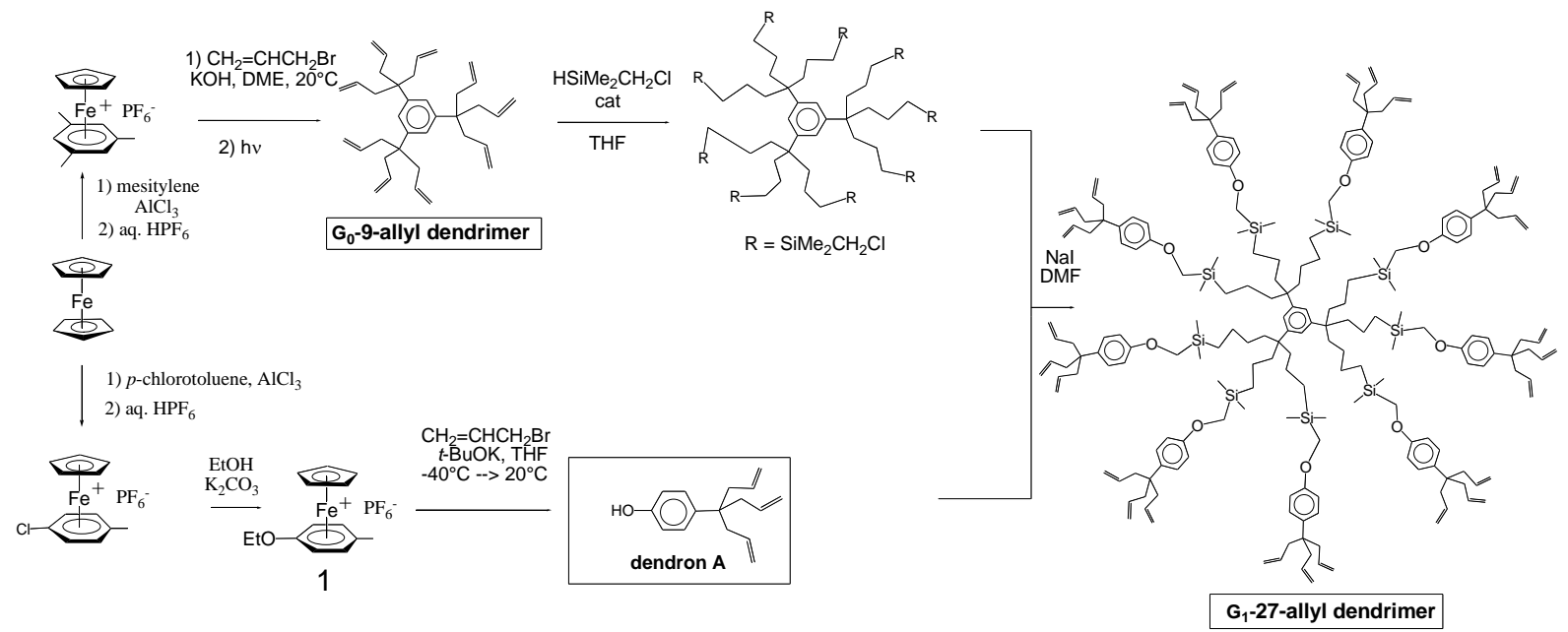

\section{Scheme 1}
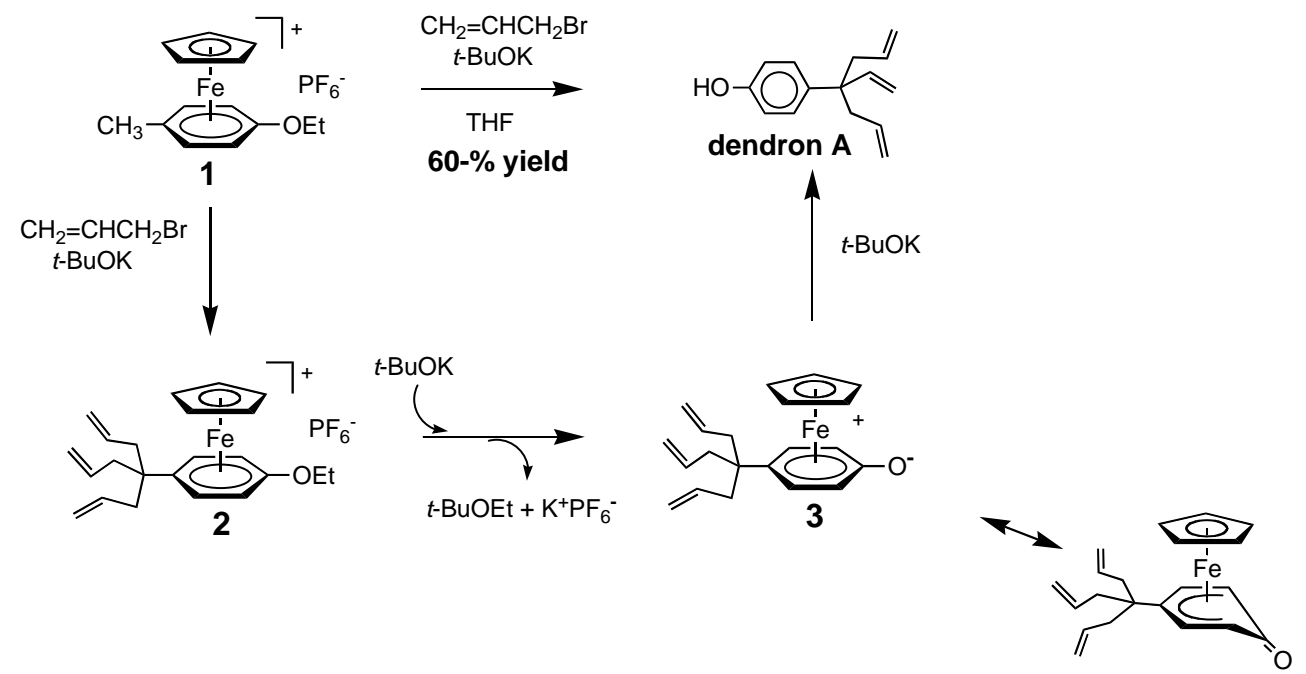

\section{Scheme 2}

We now report studies showing that the cleavage of this aryl ether complex is a nucleophilic substitution reaction of potassium tert-butoxide, and we examine the influence of the medium on this reaction, in particular that of salts. 


\section{Results}

\section{a) Synthesis of dendron $\mathrm{A}, \mathrm{p} . \mathrm{HOC}_{6} \mathrm{H}_{4} \mathrm{C}\left(\mathrm{CH}_{2} \mathrm{CH}=\mathrm{CH}_{2}\right)_{3}$}

As we have already reported, ${ }^{10,11}$ the reaction shown in Scheme 2 proceeds between $-50^{\circ} \mathrm{C}$ and room temperature, and the best yields in the synthesis of dendron A are around $60 \%$. The same reaction can be carried out for other aryl ether complexes with and without methyl group in para position on the arene ligand under conditions that we are describing and scrutinizing in the present article. The methyl group in para position serves as a source of triallyl tripod in order to multiply the number of branches of the dendrimers from one generation to the next.

b) $\mathrm{CpFe}^{+}$-induced cleavage of aryl ethers in the absence methyl group in para position on the arene ligand.

In the absence of methyl group on the phenyl ring, the aryl ether cleavage is not marred by the deprotonation. Thus, reaction of $t$-BuOK at room temperature with the aryl ether complexes $\left[\mathrm{FeCp}\left(\eta^{6}-\mathrm{C}_{6} \mathrm{H}_{5} \mathrm{OR}\right)\right]\left[\left[\mathrm{PF}_{6}\right], \mathbf{4}\right.$, does not lead to any cleavage product. For instance, with the anisole complex $\left[\mathrm{FeCp}\left(\eta^{6}-\mathrm{C}_{6} \mathrm{H}_{5} \mathrm{OCH}_{3}\right)\right]\left[\left[\mathrm{PF}_{6}\right]\right.$, 4a, total decomplexation of anisole is observed, its yield being quantitative. The only way to obtain the cleaved phenoxy complex $\left[\mathrm{Fe}^{+} \mathrm{Cp}\left(\eta^{6}\right.\right.$ $\left.\mathrm{C}_{6} \mathrm{H}_{5} \mathrm{O}^{-}\right)$], 5 , in the absence of the methyl group in para position is to carry out the reaction in the presence of a stoichiometric amount of a salt such as $\left[n-\mathrm{Bu}_{4} \mathrm{~N}\right]\left[\mathrm{PF}_{6}\right]$. The reaction can be carried out on various aryl ether iron complexes, $i$. e. with various exo-cyclic alkyl, aryl or benzyl substituents. The fragile orange oxocyclohexadienyl complex $\left[\mathrm{FeCp}\left(\eta^{5}-\mathrm{C}_{6} \mathrm{H}_{5} \mathrm{O}\right)\right], \mathbf{5}$, (mesomeric phenolate form: $\left[\mathrm{Fe}^{+} \mathrm{Cp}\left(\eta^{6}-\mathrm{C}_{6} \mathrm{H}_{5} \mathrm{O}^{-}\right)\right]$) resulting from the these cleavage reactions is known, ${ }^{10,11,15}$ as well as its $\mathrm{Cp}^{* 12}$ and $\mathrm{Ru}^{16}$ analogues $\left(\mathrm{Cp} *=\eta^{5}-\mathrm{C}_{5} \mathrm{Me}_{5}\right)$. It is obtained in $20 \%$ to $25 \%$ yield, along with $55 \%$ of free phenol and $20 \%$ of decoordinated aryl ether. $\mathrm{KBr}$ and the aryl ethers $t$-BuOR are also obtained (Scheme 3). The use of $\mathrm{K}_{2} \mathrm{CO}_{3}$ in THF, DMSO or $\mathrm{MeOH}$ instead of $t$-BuOK does not lead to any aryl ether cleavage in the same complex, even in the presence of $\left[n-\mathrm{Bu}_{4} \mathrm{~N}\right]\left[\mathrm{PF}_{6}\right]$. 


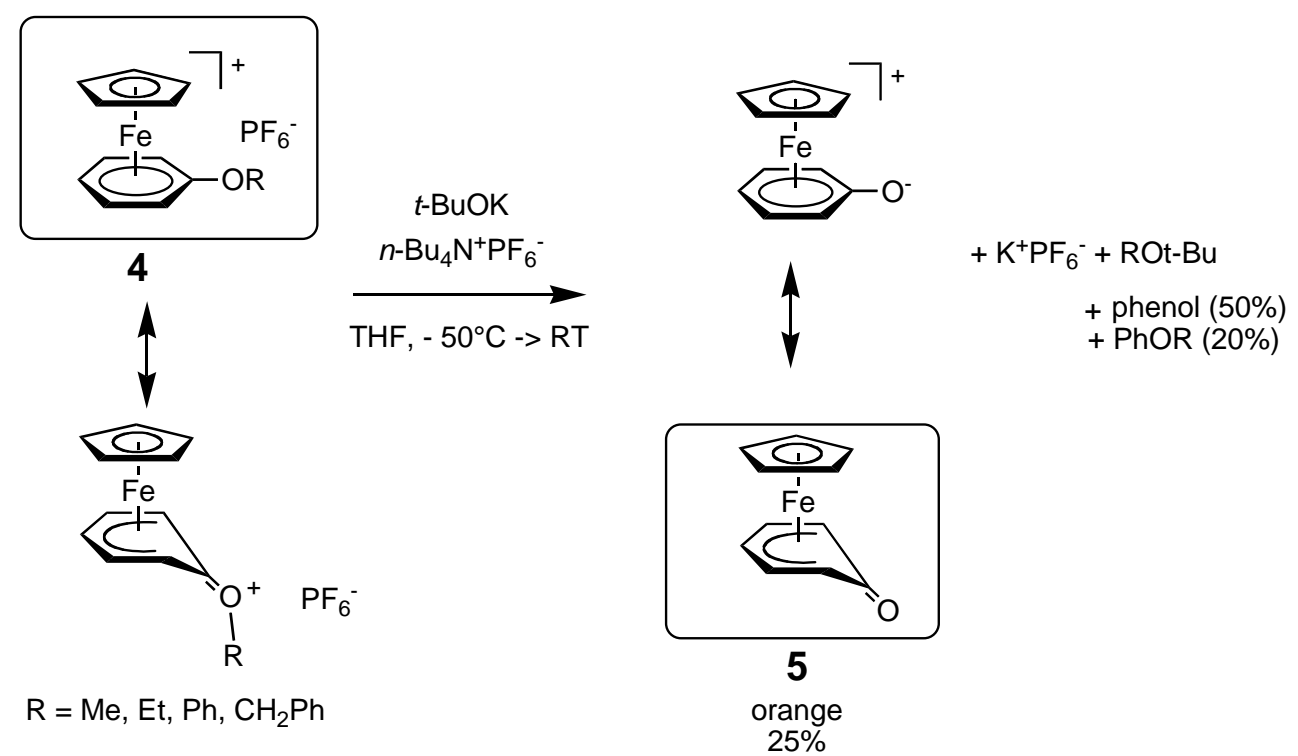

\section{Scheme 3}

c) Ion pairing, charge transfer and electron transfer between a cationic aryl ether complex and $t$-BuOK.

Reaction between the aryl ether complex $\left[\mathrm{FeCp}\left\{\eta^{6}\right.\right.$ p. $\left.\left.\mathrm{CH}_{2}=\mathrm{CHCH}_{2} \mathrm{OC}_{6} \mathrm{H}_{4} \mathrm{C}\left(\mathrm{CH}_{2} \mathrm{CH}=\mathrm{CH}_{2}\right)_{3}\right\}\right]\left[\mathrm{PF}_{6}\right], \mathbf{6}$, and $t$-BuOK in THF at room temperature does not lead to any aryl ether cleavage but, as with the parent aryl ether complex $\left[\mathrm{FeCp}\left(\eta^{6}\right.\right.$ $\left.\left.\mathrm{C}_{6} \mathrm{H}_{5} \mathrm{OCH}_{3}\right)\right]\left[\mathrm{PF}_{6}\right], \mathbf{1}$, only decomplexation is obtained; actually even at $0^{\circ} \mathrm{C}$, quantitatively decomplexation is obtained in 20 minutes. On the other hand, if the reaction is carried out at $50^{\circ} \mathrm{C}$, mixing $t$-BuOK with this complex yields an intense purple color. This purple reaction mixture was allowed to stir for $2 \mathrm{~h}$, then it was extracted, and the starting complex was quantitatively recovered. We conclude that the intense purple color is due to a charge-transfer complex $^{14} 7$ between the cationic aryl ether complex and $t$-BuOK in THF that is stable at $50^{\circ} \mathrm{C}$. When this purple reaction mixture was allowed to warm up from $-50^{\circ} \mathrm{C}$ to $0^{\circ} \mathrm{C}$, the color of the solution turned forest-green, the typical color of the 19-electron [ $\mathrm{Fe}^{\mathrm{I}} \mathrm{Cp}\left(\eta^{6}\right.$-arene $)$ ] complexes ${ }^{9}$ resulting from thermal electron transfer between the two partners within the chargetransfer complex. These forest-green $\mathrm{Fe}^{\mathrm{I}}$ complexes are usually obtained by $\mathrm{Na} / \mathrm{Hg}$ reduction (single-electron reduction) of the 18 -electron cationic precursors $\left[\mathrm{Fe}^{\mathrm{II}} \mathrm{Cp}\left(\eta^{6}\right.\right.$-arene) $]\left[\mathrm{PF}_{6}\right] .{ }^{9}$ In the case of aryl ethers (and in other cases when an heteroatom is present in the exocyclic position), however, the green 19-electron [Fe ${ }^{\mathrm{I}} \mathrm{Cp}\left(\eta^{6}\right.$-arene)] complexes such as $\mathbf{8}$ are thermally unstable at $0^{\circ} \mathrm{C}$ and rapidly lead to decomplexation, yielding $\mathbf{9}$, at this temperature (the exocyclic heteroatom is a potential monodentate $\sigma$ ligand, and $\sigma$ coordination is a strong additional driving force for the decomplexation of the 19 -electron $\pi$ complex). ${ }^{17}$ Indeed, the forest-green solution of 8 obtained in the present case turns black below room temperature (due to the formation of 
$\mathrm{Fe}^{0}$ precipitate) and also leads to complete decomplexation observed after extraction at ambient temperature (Scheme 4).

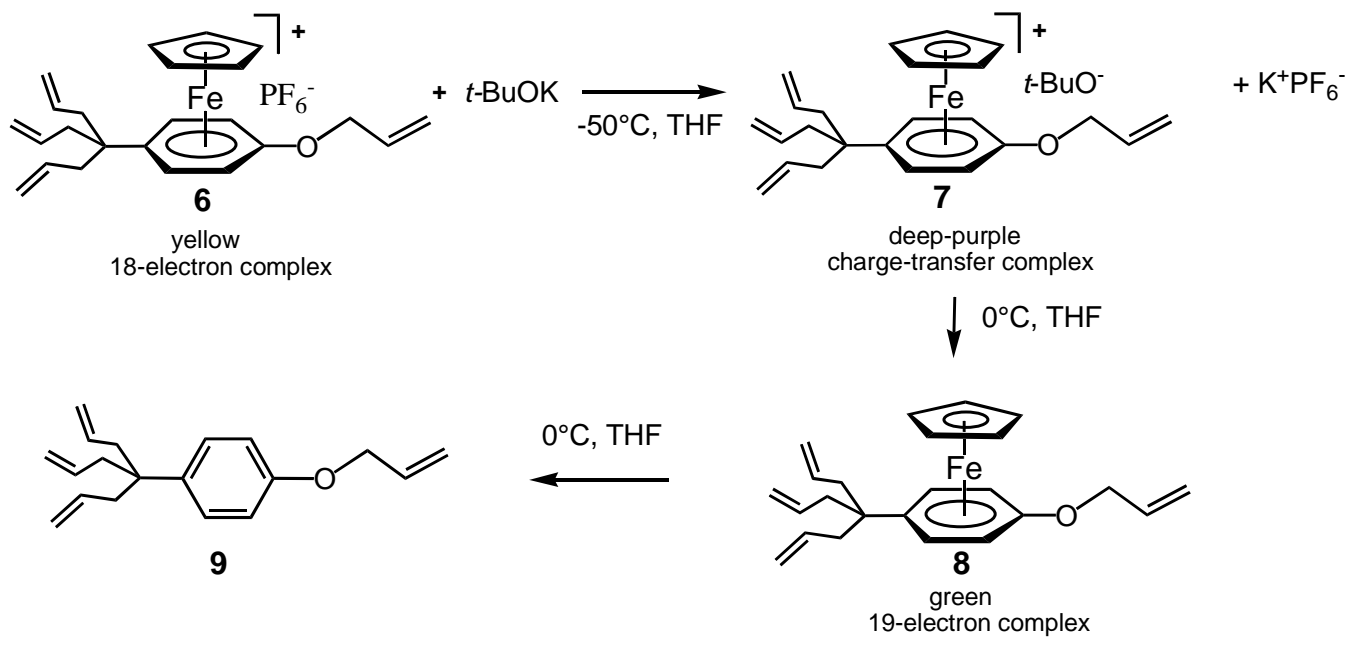

\section{Scheme 4}

d) Cleavage of the aryl ether complex $\left[\mathrm{FeCp}\left\{\eta^{6}\right.\right.$ p. $\left.\left.\mathrm{CH}_{2}=\mathrm{CHCH}_{2} \mathrm{OC}_{6} \mathrm{H}_{4} \mathrm{C}\left(\mathrm{CH}_{2} \mathrm{CH}=\mathrm{CH}_{2}\right)_{3}\right\}\right]\left[\left[\mathrm{PF}_{6}\right], 6\right.$, in THF in the presence of $\left[n-\mathrm{Bu}_{4} \mathrm{~N}\right]\left[\mathrm{PF}_{6}\right]$ or other salts and study of the influence of the nature of the salt.

These reactions were carried out exactly in the same conditions with the same aryl ether complex as above at $-50^{\circ} \mathrm{C}$, i.e. under the conditions leading to the formation of the chargetransfer complex, then to the electron-transfer product, but now in the presence of a salt whose nature was varied. As in the case of the study of the cleavage of the aryl ether in the parent complex, the cleavage by $t$-BuOK only occurs in the presence of a salt, and the nature of the added salt is important in determining the proportion of cleaved product. The salt that is the most favorable for the cleavage is $\left[n-\mathrm{Bu}_{4} \mathrm{~N}\right]\left[\mathrm{PF}_{6}\right]$; this salt was already very favorable for the cleavage of the parent aryl ether complex, and the results with various salts are gathered in Table 1 and Scheme 5. All the salts used lead to some cleavage whose amount varies with the nature of the salt. Even $\mathrm{NaCl}$ induces cleavage, although the size increase of the anion of the salt improves cleavage. 


\section{Table 1}

\begin{tabular}{|c|c|c|c|c|}
\hline & MX & $\begin{array}{c}\%\left[\mathrm{Fe}^{+} \mathrm{Cp}\left(\eta^{6} \text {-arylO }\right)\right] \\
\mathbf{3}\end{array}$ & $\begin{array}{c}\text { Free aryl } \\
\text { ether } \mathbf{9}\end{array}$ & $\begin{array}{c}\text { Starting } \\
\text { complex } \mathbf{6}\end{array}$ \\
\hline 1 & $\mathrm{NaCl}$ & 29 & 43 & 23 \\
\hline 2 & $\mathrm{NaBr}$ & 40 & 52 & 14 \\
\hline 3 & $\mathrm{NaI}$ & 50 & 10 & 23 \\
\hline 4 & $\mathrm{NaPF}_{6}$ & & & 75 \\
\hline 5 & $\mathrm{KCl}$ & 32 & 57 & 7 \\
\hline 6 & $\mathrm{KBr}$ & 42 & 47 & \\
\hline 7 & $\mathrm{KI}$ & 23 & 67 & \\
\hline 8 & $\mathrm{KPF}_{6}$ & 19 & 56 & 20 \\
\hline 9 & $\mathrm{CsCl}$ & 30 & 70 & \\
\hline 10 & $\mathrm{CsBr}$ & 31 & 65 & \\
\hline 11 & CsI & 27 & 73 & \\
\hline 12 & $\mathrm{CsPF}_{6}$ & 34 & 65 & \\
\hline 13 & $n-\mathrm{Bu}_{4} \mathrm{NCl}$ & 25 & 71 & \\
\hline 14 & $n-\mathrm{Bu}_{4} \mathrm{NBr}$ & 15 & 69 & \\
\hline 15 & $n-\mathrm{Bu}_{4} \mathrm{NI}$ & 24 & 66 & \\
\hline 16 & $n-\mathrm{Bu}_{4} \mathrm{NPF}_{6}$ & 61 & 32 & \\
\hline
\end{tabular}

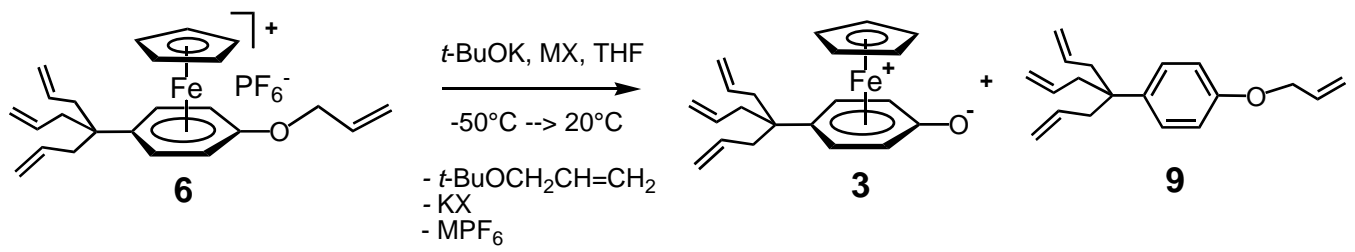

\section{Scheme 5}

\section{Discussion}

\section{Cleavage of aryl ethers}

The cleavage of aryl ethers under acidic conditions is well documented. ${ }^{18}$ On the other hand, it is extremely difficult under basic conditions, requiring temperatures around $200^{\circ} \mathrm{C}$ with very low reaction yields, ${ }^{19}$ except if strong electron-withdrawing nitro groups are present on the arene. ${ }^{20}$ Aromatic nucleophilic substitution reactions are also strongly favored when the aromatic is coordinated as a $\pi$-hexahapto ligand to 12-electron organometallic groups. Nucleophilic reactions are all the easier as the 12-electron organometallic moiety is more electron withdrawing $\left(\mathrm{Cr}(\mathrm{CO})_{3}<(\mathrm{FeCp})^{+}<\mathrm{Mn}(\mathrm{CO})_{3}{ }^{+}\right) .^{20-22} \mathrm{The} \mathrm{CpFe}^{+}$fragment is excellent for this purpose, because its cationic form provides a strong activation, and these 18-electron complexes 
$\left[\mathrm{Fe}^{\mathrm{II}} \mathrm{Cp}\left(\eta^{6} \text {-arene }\right)\right]^{+}$are very easily accessible, abundant and robust. $^{22}$ Indeed, nucleophilic reactions are well documented with these complexes, especially the nucleophilic substitution of chloride by a variety of $\mathrm{O}, \mathrm{N}$ and $\mathrm{S}$ nucleophiles under very mild conditions (even in water). ${ }^{23}$

\section{The key role of ion pairing in the nucleophilic property of the anion t-BuO-}

Whereas potassium tert-butoxide is an excellent base for the facile deprotonation of such iron complexes of polymethylarenes, the present study shows that it cannot cleave the coordinated aryl ether per se, but the presence of $\left[n-\mathrm{Bu}_{4} \mathrm{~N}\right]\left[\mathrm{PF}_{6}\right]$ is required. The solubility of $t$-BuOK in THF at $-50^{\circ} \mathrm{C}$ and below $0^{\circ} \mathrm{C}$ is very low (i.e. the concentration of contact ion pair in THF solution must be very low, eq. 3) so that $t$-BuOK in THF suspension is not efficient enough as a nucleophile for heterolytic C-O cleavage.

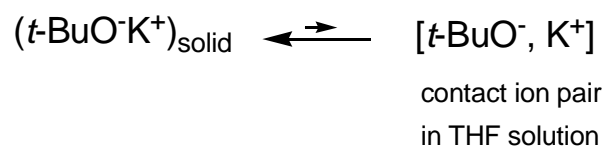

In the presence of $\left[n-\mathrm{Bu}_{4} \mathrm{~N}\right]\left[\mathrm{PF}_{6}\right]$, exchange of ions among the ion pairs must proceed to provide the contact ion pair $\left[n-\mathrm{Bu}_{4} \mathrm{~N}^{+}, t-\mathrm{BuO}^{-}\right]$that is soluble in THF. The enhanced reactivity is this later ion pair compared to $t-\mathrm{BuO}^{-} \mathrm{K}^{+}$results from its enhanced THF solubility and weaker electrostatic bonding between the anion $t-\mathrm{BuO}^{-}$and the cation $n-\mathrm{Bu}_{4} \mathrm{~N}^{+}$due to the large size of the latter compared to $\mathrm{K}^{+}$(Scheme 6):

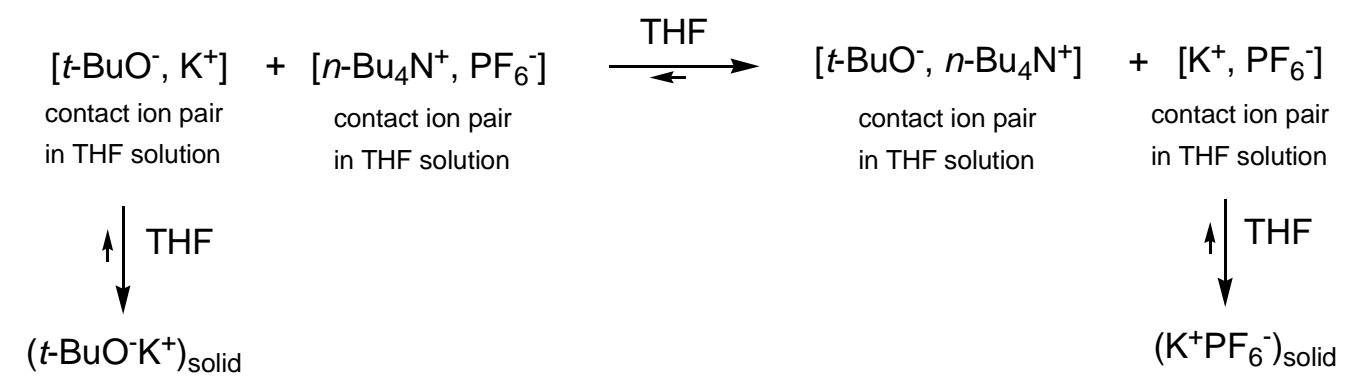

\section{Scheme 6}

The nucleophilic substitution is considerably easier in the cationic iron aryl ether complex than in the free organic ligand, as can be seen from the mesomeric oxenium form drawn in Scheme 3. The reaction between the THF-soluble contact ion pair $\left[n-\mathrm{Bu}_{4} \mathrm{~N}^{+}, t-\mathrm{BuO}^{-}\right]$and the iron salt that is only weakly soluble can be envisaged directly or via the formation of an ion pair containing both ionic reactants (Scheme 7): 


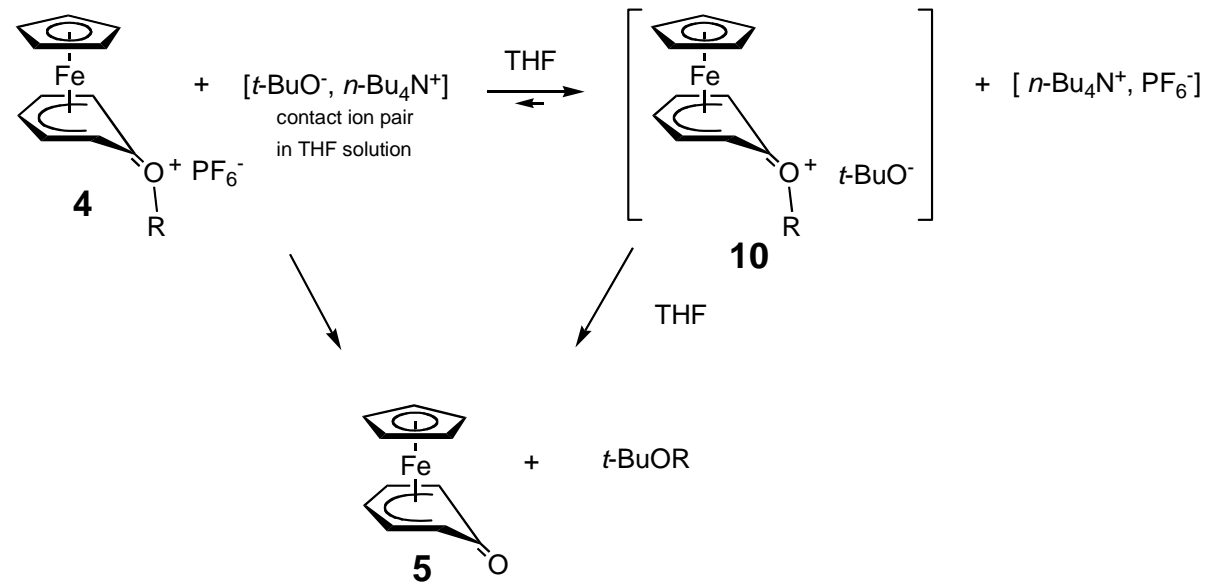

\section{Scheme 7}

\section{The key salt effect of $\mathrm{KBr}$ in the nucleophilic property of t-BuO-}

In the study of the influence of salts on the arylether cleavage (Table 1), $\mathrm{KBr}$ is not quite as efficient as $\left[n-\mathrm{Bu}_{4} \mathrm{~N}\right]\left[\mathrm{PF}_{6}\right]$, but the difference of cleavage yields in the presence of these salts (42 vs. $61 \%$ ) is not so considerable. Moreover, the influence of the concentration of $\mathrm{KBr}$ was studied by using respectively ten times less $\mathrm{KBr}(0.11$ equiv.) and 10 times more equiv. $\mathrm{KBr}(10.0$ equiv.) than the amount of $t$-BuOK. It was found that the amount of nucleophilic $\mathrm{C}-\mathrm{O}$ cleavage indeed significantly increases from $24 \%$ with 0.11 equiv. $\mathrm{KBr}$ to $39 \%$ with 1.1 equiv. $\mathrm{KBr}$ (standard conditions) and to $42 \%$ with 10 equiv. $\mathrm{KBr}$. It is noteworthy that the cation of this salt, $\mathrm{K}^{+}$, now is the same as that of the initial reagent $t$-BuOK, and thus the cation effect can no longer be invoked at this time to rationalize the improved nucleophilic property of $t$ - $\mathrm{BuO}^{-}$. One may again involve the iron pairing between the large organoiron cation and $t$ - $\mathrm{BuO}^{-}$that must occur as shown in Scheme 4, but the difference of behavior between the electron-transfer reaction of $t$ $\mathrm{BuO}^{-}$in the absence of $\mathrm{KBr}$ and its nucleophilic property in the presence of $\mathrm{KBr}$ shown in Scheme 5 remains to be explained. When $\mathrm{KBr}$ is added, three ions pairs can interchange their ions, but two of them contain $\mathrm{K}^{+}$. Thus, the ion-pairing effect can only partly induce the reaction change. On the other hand, the presence of excess $\mathrm{Br}^{-}$anions (introduced in low concentration in THF when it is associated with $\mathrm{K}^{+}$and in higher concentration when it is associated with the large solubilizing organoiron cation) and/or the heterogeneous interaction of the arylether complex $\left[\mathrm{Fe}^{\mathrm{II}} \mathrm{Cp}\left(\eta^{6}-\mathrm{ArOR}\right)\right]^{+}$with solid $\mathrm{KBr}$ particles can polarize the $\mathrm{C}-\mathrm{O}$ bond and synergistically favor the nucleophilic attack of $t-\mathrm{BuO}^{-}$to form $t$ BuOR' that has also been characterized. The possibility of an heterogeneous C-O polarization is also illustrated by the favorable salt effect on the C-O cleavage of THF-insoluble salts such as $\mathrm{Na}^{+} \mathrm{Cl}^{-}$(entry 1 of Table 1). 


\section{Nucleophilic C-O cleavage in the course of the perallylation reaction using t-BuOK and allylbromide}

When the para methyl group is present on the aryl ether ligand, the reaction with $t$-BuOK and allyl bromide yielding the phenoltriallyl brick is much more complex (8 steps), as shown in Scheme 2, and it is not necessary to introduce a salt at the very start of the reaction. Under these conditions, the multiple benzylic deprotonation-nucleophilic substitution steps (first set of steps of Scheme 2) by $t$-BuOK yield $t$ - $\mathrm{BuOH}$ and $\mathrm{KBr}$. In particular, $\mathrm{KBr}$ is produced after nucleophilic substitution of the bromide in allylbromide by the organoiron carbanion resulting from each deprotonation step. Thus, the favorable salt effect of $\mathrm{KBr}$ polarizing the $\mathrm{C}-\mathrm{O}$ bond and facilitating its nucleophilic cleavage by $t$-BuOK is present. In addition, much more $t$-BuOK is required to carry out the synthesis of the phenoltriallyl brick (cleavage + perallylation) than only to cleave the aryl ether. Indeed, in the dendron synthesis, three deprotonation steps, the nucleophilic cleavage, and the final decomplexation are all using $t$-BuOK. In addition, these deprotonation steps are producing substantial amounts of $t-\mathrm{BuOH}$, which makes the solvent mixture more polar, favoring the polarization of the $\mathrm{C}-\mathrm{O}$ bond by the $\mathrm{Br}$ - anion or/and $\mathrm{KBr}$. The composition of the medium (including $t-\mathrm{BuOH}$ and excess allylbromide and $t$-BuOK) also favors the solubility of these ionic reactants (that are little soluble in THF alone) and thus their polarizing action and reactivity.

Finally, in the case of Scheme 2 for which the desired cleaved tripodal phenol is awaited, the heterolytic cleavage is facilitated by the increased reactivity of the iron complex due to the presence of the tripod $-\mathrm{C}\left(\mathrm{CH}_{2} \mathrm{CH}=\mathrm{CH}_{2}\right)_{3}$ in para position (compared to the parent complex 5 in Scheme 3). This large organic group is both solubilizing the complex in THF and enhancing the reactivity of its counter anion because of its larger size compared to the parent complex that does not bear this bulky group. In this case, the large organoiron cation can itself play the role of the large counter cation of $t$ - $\mathrm{BuO}^{-}$(see the formation of $\mathbf{1 1}$ in Scheme 5), i.e. the role of $n-\mathrm{Bu}_{4} \mathrm{~N}^{+}$, the most favorable cation for aryl ether cleavage in the salt effect study (entry 16).

\section{Salt effect: comparison of various salts}

The influence of the other salts in table I is intermediate and in accord with the respective Lewisacid properties $^{24}$ of the ions that have been well recognized and studied in ion-pairing and salt effects: ${ }^{3}$

The cesium salts (entries 9 to 12) lead to decomplexation. This can be taken into account by the Lewis-acid character of the cesium cation favoring the dissociation of $t$-BuOK without facilitating the polarization of the aryl ether. Also, cesium salts often are dissociated, thus may not disrupt the ion pair $\left[\mathrm{Fe}^{\mathrm{II}} \mathrm{Cp}\left(\eta^{6} \text {-arene }\right)^{+}, t-\mathrm{BuO}^{-}\right]$that leads to decomplexation under the working conditions.

- $\quad$ The ammonium salts (entries 13 to 15 ), except $\left[n-\mathrm{Bu}_{4} \mathrm{~N}\right]\left[\mathrm{PF}_{6}\right]$, also lead, as cesium salts, to a high percentage of decomplexation products, for the same reasons detailed above.

- $\quad$ The presence of added $\mathrm{NaPF}_{6}$ (entry 4) does not lead to a cleavage or decomplexation reaction (i.e. the starting material is recovered). This salt is well known for inhibiting cage 
reactions by double exchange between ion pairs. ${ }^{3,17}$ Formation of $\left[\mathrm{Na}^{+}, t-\mathrm{BuO}^{-}\right]$decreases the reactivity of the anion due to a relatively strong ionic bonding, and the anion $\mathrm{PF}_{6}{ }^{-}$provided by this the salt enhances the sterile association with the organoiron cation.

- $\quad \mathrm{Na}^{+}$(entries 1 to 3 ) and $\mathrm{K}^{+}$salts (entries 5 to 8) have positive, intermediate effects on the cleavage reaction, the differences being probably provided by both differences in THF solubilities and the percentage of dissociation of the salt in THF:

$\mathrm{NaI}>\mathrm{NaBr}>\mathrm{NaCl}$, and $\mathrm{KI}>\mathrm{KCl}>\mathrm{KBr}$.

\section{Synthesis of the phenoltriallyl dendronic brick A: the complex (but powerful) Scheme 2}

In this report, we have focused on the nucleophilic cleavage reaction in the cationic aryl ether iron complexes producing the zwitterionic phenolate iron complexes. From the synthetic point of view, however, our main target is the free aromatic dendronic brick $\mathbf{A}$, p. $\mathrm{C}\left(\mathrm{CH}_{2}=\mathrm{CHCH}_{2}\right)_{3} \mathrm{CC}_{6} \mathrm{H}_{4} \mathrm{OH}$, rather than the corresponding zwitterionic iron complex $\left[\mathrm{Fe}^{\mathrm{II}} \mathrm{Cp}\left\{\eta^{5}-p . \mathrm{C}\left(\mathrm{CH}_{2} \mathrm{CHCH}_{2}\right)_{3} \mathrm{C}_{6} \mathrm{H}_{5} \mathrm{O}\right\}\right], \quad 3$, or its protonated phenol form $\left[\mathrm{Fe}^{\mathrm{II}} \mathrm{Cp}\left\{\eta^{6}-\right.\right.$ p.C $\left.\left.\left(\mathrm{CH}_{2} \mathrm{CHCH}_{2}\right)_{3} \mathrm{C}_{6} \mathrm{H}_{5} \mathrm{OH}\right\}\right]\left[\mathrm{PF}_{6}\right]$. The way to yield this organic dendron $\mathbf{A}$ from its iron complex precursor $\mathbf{3}$ is to add $t$-BuOK alone in a last step in the one-pot reaction before extraction. In this way, the last step of Scheme 2 is fulfilled. When $t$-BuOK cannot react as a base (step 1), it can reacts as a nucleophile in the presence of a suitable salt (step 2), and when it can no longer act as a nucleophile, its last possibly as a high-energy reagent is to act as an electron-transfer reagent (step 3). The present study is most useful to understand the overall Scheme 2 that gathers these three successive roles of $t$-BuOK and to help us optimize the reaction conditions of this complex multi-step one-pot key synthesis. In particular, the electrontransfer reaction (leading to decomplexation without cleavage) is preferred to the nucleophilic C$\mathrm{O}$ bond cleavage in the absence of a salt, as shown in Schemes 4 and 8 (even at low temperature), which still emphasizes the crucial importance of optimizing the favorable salt effect in order to efficiently carry out the nucleophilic C-O bond cleavage at low temperature (Scheme 8).
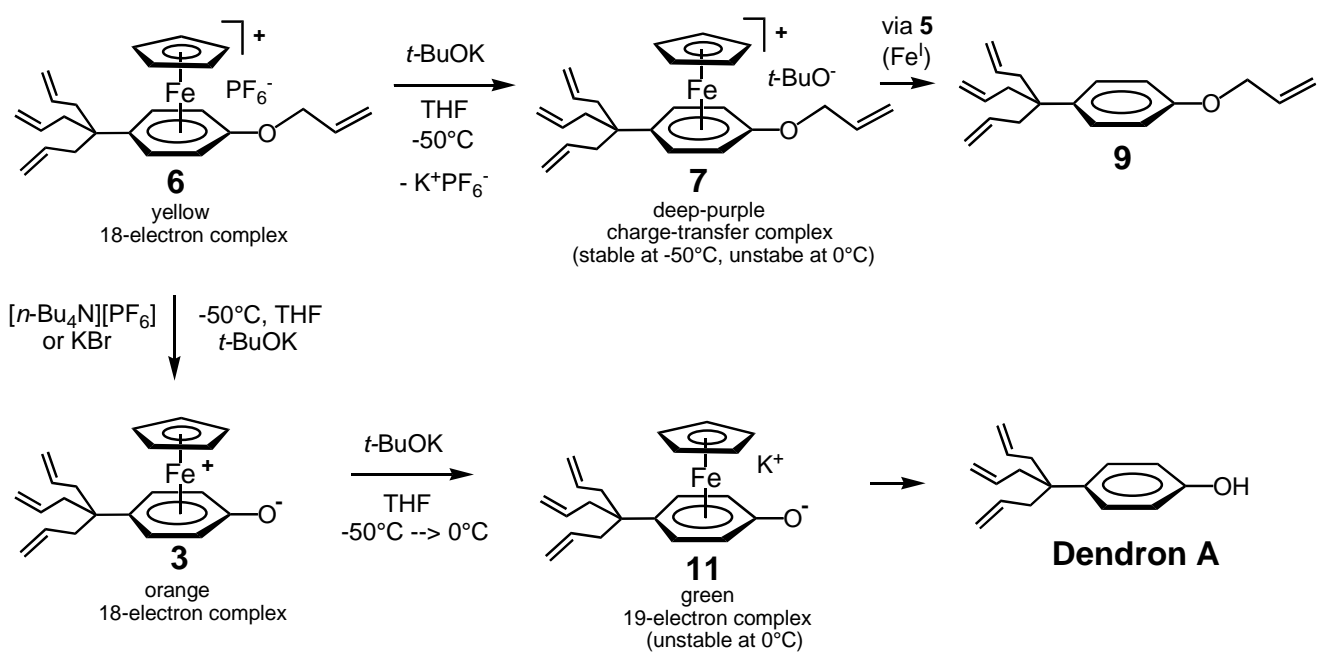

\section{Scheme 8}




\section{Conclusions}

Potassium tert-butoxide, an excellent base in THF, is not reactive enough as a nucleophile in this solvent in the absence of additive. The ionic bond between the two ions needs be disrupted for instance by the added salt $\left[n-\mathrm{Bu}_{4} \mathrm{~N}\right]\left[\mathrm{PF}_{6}\right]$ so that the tert-butoxide anion becomes more soluble and more reactive due to a weaker ionic bonding with the cation. Under these conditions, i.e. in the presence of $\left[n-\mathrm{Bu}_{4} \mathrm{~N}\right]\left[\mathrm{PF}_{6}\right]$, heterolytic cleavage of aryl ethers activated by the 12-electron fragment $\mathrm{CpFe}^{+}$occurs smoothly between $-50^{\circ} \mathrm{C}$ and room temperature. Ion exchange among the ion pairs generating $\left[n-\mathrm{Bu}_{4} \mathrm{~N}^{+}, t-\mathrm{BuO}^{-}\right]$, thus enhancing the reactivity of $t-\mathrm{BuO}^{-}$, is believed to be responsible for the desired nucleophilic substitution reaction. This conclusion can be compared to Gokel's work which had shown that the presence of 18-crown-6 rendered potassium tert-butoxide relatively nucleophilic in THF. ${ }^{8}$

In the synthesis of the phenoltriallyl dendron $\mathbf{A}$ (Scheme 2), a complex 8-step reaction, it is not necessary to add a salt. The first reason is that $\mathrm{KBr}$ is generated in situ. It is also efficient in the cleavage reaction of the parent arylether, although not quite as much as $\left[n-\mathrm{Bu}_{4} \mathrm{~N}\right]\left[\mathrm{PF}_{6}\right]$. The effect of $\mathrm{Br}^{-}$or $\mathrm{KBr}$ that polarizes the $\mathrm{C}-\mathrm{O}$ bond, favoring its cleavage, was demonstrated. The second reason is that the bulky lipophilic group $\mathrm{C}\left(\mathrm{CH}_{2} \mathrm{CH}=\mathrm{CH}_{2}\right)_{3}$, that is constructed in para position of the arene as the deprotonation-allylation reaction proceeds, favors the subsequent nucleophilic reactivity of $t$ - $\mathrm{BuO}^{-}$by both solubilizing the ion pairs of the organoiron cation and by making this organoiron cation larger.

In conclusion, potassium tert-butoxide is not a nucleophile in THF per se, but the anion t$\mathrm{BuO}^{-}$provided by potassium tert-butoxide can be rendered nucleophilic by association with large solubilizing counter cations subsequent to ion exchange among ion pairs. This was demonstrated in the present work using salt and substituent effects in the nucleophilic C-O cleavage of $\mathrm{CpFe}^{+}$ complexes of aryl ethers providing $\mathrm{CpFe}^{+}$complexes of phenolates, and in particular a phenoltriallyl dendron $\mathbf{A}$ that is a crucial brick in giant dendrimer synthesis and molecular nanoscience (Scheme 1).

\section{Experimental Section}

General Procedures. The NMR spectra were recorded with a Bruker AC-250 FT apparatus $\left({ }^{1} \mathrm{H}\right.$ : $250 \mathrm{MHz} ;{ }^{13} \mathrm{C}$ : $62 \mathrm{MHz}$ ). Reaction mixtures were treated by flash chromatography with neutral activated alumina Prolabo $50-160 \mu \mathrm{m}$ or Fluka $100-125 \mu \mathrm{m}$. with a slightly positive pressure. Pentane and ether were dried over sodium using the sodium benzophenone ketyl as the indicator. Dichloromethane was dried over $\mathrm{CaH}_{2}$, and THF was dried over $\mathrm{LiAlH}_{4}$. The solvents were distilled just before use over these drying agents under argon. Reactions were carried out in Schlenk tubes under argon in the dark. The complexes $\left[\mathrm{Fe}^{\mathrm{II}} \mathrm{Cp}\left(\eta^{6}\right.\right.$-arene] $\left[\mathrm{PF}_{6}\right]$ were synthesized as indicated in references 17, 21 and 23. Specifically, the complexes [ $\mathrm{Fe}^{\mathrm{II}} \mathrm{Cp}\left(\eta^{6}-\mathrm{PhOMe}\right]\left[\mathrm{PF}_{6}\right]$, 4a, $\quad\left[\mathrm{Fe}^{\mathrm{II}} \mathrm{Cp}\left(\eta^{6}-p \cdot \mathrm{CH}_{3} \mathrm{PhOEt}\right]\left[\mathrm{PF}_{6}\right], \quad \mathbf{4 b}, \quad\left[\mathrm{Fe}^{\mathrm{II}} \mathrm{Cp}\left(\eta^{5}-\mathrm{C}_{6} \mathrm{H}_{5} \mathrm{O}\right], \quad \mathbf{5}, \quad\left[\mathrm{Fe}^{\mathrm{II}} \mathrm{Cp}\left(\eta^{6}-\right.\right.\right.\right.$ 
p.C $\left.\left(\mathrm{CH}_{2} \mathrm{CHCH}_{2}\right)_{3} \mathrm{C}_{6} \mathrm{H}_{5} \mathrm{OCH}_{2} \mathrm{CHCH}_{2}\right]\left[\mathrm{PF}_{6}\right], 6$ and $\left[\mathrm{Fe}^{\mathrm{II}} \mathrm{Cp}\left(\eta^{6}-p . \mathrm{C}\left(\mathrm{CH}_{2} \mathrm{CHCH}_{2}\right)_{3} \mathrm{C}_{6} \mathrm{H}_{5} \mathrm{O}\right]\right.$, dendron A, were synthesized and characterized as described earlier. ${ }^{10,12}$

Reaction of $\left[\mathbf{F e}^{\mathrm{II}} \mathbf{C p}\left(\eta^{6}-\mathrm{PhOMe}\right]\left[\mathrm{PF}_{6}\right]\right.$, 4a, with $\boldsymbol{t}$-BuOK. $\left[\mathrm{Fe}^{\mathrm{II}} \mathrm{Cp}\left(\eta^{6}-\mathrm{PhOMe}\right]\left[\mathrm{PF}_{6}\right], \mathbf{4 a}(0.371\right.$ g, $1 \mathrm{mmol})$ and $t$-BuOK $(0.112 \mathrm{~g}, 1 \mathrm{mmol})$ were deaerated in a Schlenk tube, then $10 \mathrm{~mL}$ distilled THF was introduced. The reaction mixture was stirred for one day at $25^{\circ} \mathrm{C}$, the solvent was removed under vacuum, the solid residue was dissolved in $5 \mathrm{~mL}$ dichloromethane, and this solution was filtered, then dried over $\mathrm{Na}_{2} \mathrm{SO}_{4}$ and the filtered solution was evaporated under vacuum. The residue was chromatographied using an alumina/product mass ratio of 40 . No iron complex, but only anisole, resulting from quantitative decomplexation, was obtained and characterized and titrated by ${ }^{1} \mathrm{H}$ NMR.

The same reaction was carried out under these conditions in the presence of one mmol $\left[n-\mathrm{Bu}_{4} \mathrm{~N}\right]\left[\mathrm{PF}_{6}\right]$. Extraction and purification as above yielded, after chromatographic elution with methanol and washing with anhydrous ether, $53 \mathrm{mg}$ of $\left[\mathrm{Fe}{ }^{\mathrm{II}} \mathrm{Cp}\left(\eta^{5}-\mathrm{C}_{6} \mathrm{H}_{5} \mathrm{O}\right], 5\right.$, as an orange resin (25\%) characterized by IR ( $\left.v_{\mathrm{CO}}: 1545 \mathrm{~cm}^{-1}\right),{ }^{1} \mathrm{H}$ and ${ }^{13} \mathrm{C} \mathrm{NMR},{ }^{12}$ and elemental analysis: calc. for $\mathrm{C}_{11} \mathrm{H}_{10} \mathrm{OFe}$. $\mathrm{H}_{2} \mathrm{O}$ : C,56.93; H, 5.21; Fe, 24.06; found: C, 56.58; H, 5.17; Fe, 23.82.

Ether washing yielded $55 \mathrm{mg}$ of free phenol as white crystals (25\%) and $22 \mathrm{mg}$ of free anisole from slow evaporation of the solvent (20\%), both characterized by ${ }^{1} \mathrm{H}$ NMR.

Synthesis of $\left[\mathrm{Fe}^{\mathrm{II}} \mathbf{C p}\left(\eta^{6}-p . \mathbf{C}\left(\mathbf{C H}_{2} \mathbf{C H C H}_{2}\right)_{3} \mathbf{C}_{6} \mathbf{H}_{5} \mathbf{O C H}_{2} \mathbf{C H C H}_{2}\right]\left[\mathbf{P F}_{6}\right]\right.$ (6). The complex [FeCp $\left.\left(\eta^{6}-p . \mathrm{EtOC}_{6} \mathrm{H}_{4} \mathrm{CH}_{3}\right)\right], \mathbf{1},(5 \mathrm{~g}, 13 \mathrm{mmol}$.) and $t$-BuOK (22.4 g, $0.2 \mathrm{~mol})$ were introduced in a flamed Schlenk tube and deaerated, then allyl bromide (18 mL, $0.2 \mathrm{~mol})$ in $70 \mathrm{~mL}$ THF was added at $-50^{\circ} \mathrm{C}$. The reaction mixture was stirred for three days at room temperature. Then $t-$ $\mathrm{BuOK}(22.4 \mathrm{~g}, 0.2 \mathrm{~mol})$ and allyl bromide $(18 \mathrm{~mL}, 0.2 \mathrm{~mol})$ were successively added at $-20^{\circ} \mathrm{C}$, and the reaction medium was stirred for three days at ambient temperature. This operation was then carried out once more, then solvent was removed under vacuum, the residue was mixed with $10 \mathrm{~mL}$ dichloromethane, this mixture was filtered, the organic filtrate was washed with aq. $\mathrm{HPF}_{6}$, the organic layer was decanted and dried over $\mathrm{Na}_{2} \mathrm{SO}_{4}$, filtered and the solvent was removed under vacuum. The residue was washed by stirring with $3 \times 10 \mathrm{~mL}$ pentane, and the remaining solid residue was chromatographied on an alumina column using dichloromethane as eluant, which yielded $0.361 \mathrm{~g}(8 \%)$ of $\left[\mathrm{Fe}^{\mathrm{II}} \mathrm{Cp}\left\{\eta^{6}-p \cdot \mathrm{C}\left(\mathrm{CH}_{2} \mathrm{CHCH}_{2}\right)_{3} \mathrm{C}_{6} \mathrm{H}_{5} \mathrm{O}\right\}\right]$, 3, as a red resin characterized by IR, ${ }^{1} \mathrm{H}$ and ${ }^{13} \mathrm{C}$ NMR and elemental analysis, see ref. 12) and $5.9 \mathrm{~g}$ (85\%, of $\left[\mathrm{Fe}^{\mathrm{II}} \mathrm{Cp}\left(\eta^{6}-p . \mathrm{C}\left(\mathrm{CH}_{2} \mathrm{CHCH}_{2}\right)_{3} \mathrm{C}_{6} \mathrm{H}_{5} \mathrm{OCH}_{2} \mathrm{CHCH}_{2}\right]\left[\mathrm{PF}_{6}\right], \mathbf{6}\right.$, as a yellow-brown powder:

${ }^{1} \mathrm{H}$ NMR $\left(\mathrm{CD}_{3} \mathrm{COCD}_{3}, 250 \mathrm{MHz}\right): \delta_{\mathrm{ppm}}: 6.28-6.32\left(\mathrm{~m}, 4 \mathrm{H}, \mathrm{C}_{6} \mathrm{H}_{4}\right), 5.94-6.10(\mathrm{~m}, 1 \mathrm{H}$, $\mathrm{OCH}_{2} \mathrm{CH}=\mathrm{CH}_{2}$ ), 5.88-5.91 (m, 3H, $\left.\mathrm{CH}_{2} \mathrm{CH}=\mathrm{CH}_{2}\right), 5.35$ and $5.39\left(\mathrm{~m}, 2 \mathrm{H}, \mathrm{CH}_{2}=\mathrm{CHCH}_{2} \mathrm{O}\right)$, 5.15$5.23\left(\mathrm{~m}, 6 \mathrm{H}, \mathrm{CH}_{2}=\mathrm{CHCH}_{2}\right), 5.10$ (s, $\left.5 \mathrm{H}, \mathrm{C}_{5} \mathrm{H}_{5}\right), 4.87$ (d, $\left.2 \mathrm{H}, \mathrm{CH}_{2} \mathrm{O}\right), 2.60\left(\mathrm{~d}, 6 \mathrm{H}, \mathrm{CH}_{2}\right) ;{ }^{13} \mathrm{C}$ NMR: $\left(\mathrm{CD}_{3} \mathrm{COCD}_{3}, 62.9 \mathrm{MHz}\right.$ ): $\delta_{\mathrm{ppm}}: 134.2$ (quaternary $\left.\mathrm{C}-\mathrm{O}, \mathrm{C}_{6} \mathrm{H}_{4}\right), 133.2$ and 132.8 $\left(\mathrm{CH}=\mathrm{CH}_{2}\right), 120.1$ and $119.9\left(\mathrm{CH}=\mathrm{CH}_{2}\right), 111.4$ (quaternary $\mathrm{C}$-C, $\left.\mathrm{C}_{6} \mathrm{H}_{4}\right), 84.4(\mathrm{CH}$ ortho $(\mathrm{O})$, $\left.\mathrm{C}_{6} \mathrm{H}_{4}\right), 77.7(\mathrm{Cp}), 74.0\left(\mathrm{CH}\right.$ meta $\left.(\mathrm{O}), \mathrm{C}_{6} \mathrm{H}_{4}\right), 71.0\left(\mathrm{CH}_{2} \mathrm{O}\right)$, 43.5 (quaternary benzylic $\left.C\right)$; 43.0 $\left(\mathrm{CH}_{2}\right)$ Analysis calc. for $\mathrm{C}_{24} \mathrm{H}_{29} \mathrm{OFePF}_{6}$ : C, 53.92; H, 5.46; Fe, 10.47; found: C, 53.96; H, 5.48; Fe, 10.32 . 


\section{Study of the C-O cleavage in $\left[\mathrm{Fe}^{\mathrm{II}} \mathrm{Cp}\left\{\eta^{6}-p . \mathrm{C}\left(\mathrm{CH}_{2} \mathrm{CHCH}_{2}\right)_{3} \mathrm{C}_{6} \mathrm{H}_{4} \mathrm{OCH}_{2} \mathrm{CHCH}_{2}\right\}\right]\left[\mathrm{PF}_{6}\right]$ (6).} Low-temperature attempt: $\left[\mathrm{Fe}^{\mathrm{II}} \mathrm{Cp}\left(\eta^{6}-p \cdot \mathrm{C}\left(\mathrm{CH}_{2} \mathrm{CHCH}_{2}\right)_{3} \mathrm{C}_{6} \mathrm{H}_{4} \mathrm{OCH}_{2} \mathrm{CHCH}_{2}\right]\left[\mathrm{PF}_{6}\right], 6(0.534 \mathrm{~g}\right.$, $1 \mathrm{mmol})$ and $t$-BuOK $(0.123 \mathrm{~g}, 1.1 \mathrm{mmol})$ were introduced in a flamed Schlenk tube and deaerated, then $10 \mathrm{~mL}$ THF was added at $-50^{\circ} \mathrm{C}$, and the reaction medium became deep-purple and was stirred for $2 \mathrm{~h}$ at $-50^{\circ} \mathrm{C}$, then $2 \mathrm{~mL}$ of a diluted aqueous solution of $\mathrm{HPF}_{6}$ was added at $50^{\circ} \mathrm{C}$, and the reaction mixture was allowed to warm up to room temperature. Dichloromethane $(20 \mathrm{~mL})$ was added, the organic phase was separated, washed with water, dried over $\mathrm{Na}_{2} \mathrm{SO}_{4}$, filtered, which gives the complete recovery of the starting complex as a yellow-brown powder (0.534 g, 100\%).

Decomplexation by $t$-BuOK in THF at room temperature. $\left[\mathrm{Fe}^{\mathrm{II}} \mathrm{Cp}\left(\eta^{6}-p . \mathrm{C}\left(\mathrm{CH}_{2} \mathrm{CHCH}_{2}\right)_{3} \mathrm{C}_{6} \mathrm{H}_{4} \mathrm{OCH}_{2} \mathrm{CHCH}_{2}\right]\left[\mathrm{PF}_{6}\right], \mathbf{6},(0.534 \mathrm{~g}, 1 \mathrm{mmol})\right.$ and $t-\mathrm{BuOK}(0.123$ g, $1.1 \mathrm{mmol}$ ) were introduced in a flamed Schlenk tube and deaerated, then $10 \mathrm{~mL}$ THF was added at $-50^{\circ} \mathrm{C}$, and the reaction medium was stirred for one day at room temperature, then 2 $\mathrm{mL}$ of a diluted aqueous solution of $\mathrm{HPF}_{6}$ was added at $-50^{\circ} \mathrm{C}$, and the reaction mixture was allow to warm up to room temperature. Dichloromethane $(20 \mathrm{~mL})$ was added, the organic phase was separated, washed with water, dried over $\mathrm{Na}_{2} \mathrm{SO}_{4}$, filtered, which gave a quantitative yield of the decomplexation product $p . \mathrm{C}\left(\mathrm{CH}_{2} \mathrm{CH}=\mathrm{CH}_{2}\right)_{3} \mathrm{C}_{6} \mathrm{H}_{4} \mathrm{OCH}_{2} \mathrm{CH}=\mathrm{CH}_{2}, \quad 9$, as an oil $(0.269 \mathrm{~g}$, $100 \%) .{ }^{1} \mathrm{H}$ NMR $\left(\mathrm{CD}_{3} \mathrm{COCD}_{3}, 250 \mathrm{MHz}\right): \delta_{\mathrm{ppm}}: 6.83-6.66\left(\mathrm{~m}, 4 \mathrm{H}, \mathrm{C}_{6} \mathrm{H}_{4}\right), 5.98(\mathrm{~m}, 1 \mathrm{H}$, $\left.\mathrm{OCH}_{2} \mathrm{CHCH}_{2}\right), 5.66\left(\mathrm{~m}, 3 \mathrm{H}, \mathrm{CH}_{2} \mathrm{CH}=\mathrm{CH}_{2}\right), 5.33\left(\mathrm{~m}, 2 \mathrm{H}, \mathrm{CH}_{2}=\mathrm{CHCH}_{2} \mathrm{O}\right), 4.67(\mathrm{~m}, 6 \mathrm{H}$, $\left.\mathrm{CH}_{2}=\mathrm{CHCH}_{2}\right), 4.65\left(\mathrm{~d}, 2 \mathrm{H}, \mathrm{CH}_{2} \mathrm{O}\right), 2.26\left(\mathrm{~d}, 6 \mathrm{H}, \mathrm{CH}_{2}\right)$. Analysis calc. for $\mathrm{C}_{19} \mathrm{H}_{24} \mathrm{O}: \mathrm{C}, 85.03 ; \mathrm{H}$, 9.01; found: C, 84.72; $\mathrm{H}, 8.78$.

Low-temperature $\mathbf{C}-\mathrm{O}$ cleavage by $\boldsymbol{t}$-BuOK in THF in the presence of a salt (see the entries to Table 1). [ $\mathrm{Fe}^{\mathrm{II}} \mathrm{Cp}\left(\eta^{6}-p \cdot \mathrm{C}\left(\mathrm{CH}_{2} \mathrm{CHCH}_{2}\right)_{3} \mathrm{C}_{6} \mathrm{H}_{4} \mathrm{OCH}_{2} \mathrm{CHCH}_{2}\right]\left[\mathrm{PF}_{6}\right], 6$, $(0.534 \mathrm{~g}, 1 \mathrm{mmol}), 10$ mmol of a salt MX (see Table 1$)$ and $t$-BuOK $(0.123 \mathrm{~g}, 1.1 \mathrm{mmol})$ were introduced in a flamed Schlenk tube and deaerated, then $10 \mathrm{~mL}$ THF was added at $-50^{\circ} \mathrm{C}$, and the reaction medium was warmed up and stirred for one day at room temperature. The solvent was removed under vacuum, dichloromethane $(20 \mathrm{~mL})$ was added, and the resulting mixture was filtered. Then, 2 $\mathrm{mL}$ of a diluted aqueous solution of $\mathrm{HPF}_{6}$ was added to the filtrate, the organic phase was separated, washed with water, dried over $\mathrm{Na}_{2} \mathrm{SO}_{4}$, and filtered. The solvent was removed under vacuum, and the residue was chromatographied on an alumina column. Elution using pentane yielded the free aromatic decomplexation product product p. $\mathrm{C}\left(\mathrm{CH}_{2} \mathrm{CH}=\mathrm{CH}_{2}\right)_{3} \mathrm{C}_{6} \mathrm{H}_{4} \mathrm{OCH}_{2} \mathrm{CH}=\mathrm{CH}_{2} \mathbf{9}$, as an oil, then elution with dichloromethane gave the starting complex as a yellow-brown powder, and finally elution with methanol yielded the zwitterionic phenolate complex A resulting from C-O cleavage as a red resin (the compounds were characterized by ${ }^{1} \mathrm{H}$ NMR, vide supra, and the \% obtained are given for the various salts in Table 1). In the case of the salt $\mathrm{KBr}$, the effect of the concentration of this salt in the reaction was studied by varying the number of $\mathrm{KBr}$ equivalent from 0.11 to 1.1 (standard condition) and 10.0, the amounts of the other reactants being unchanged and indicated above. The \% of cleaved phenolate complex and free aromatic resulting from decomplexation were respectively 24 and 
$59 \%$ with 0.11 equiv. $\mathrm{KBr}, 39$ and $45 \%$ with 1.1 equiv. $\mathrm{KBr}$ and 42 and $47 \%$ with 10 equiv. $\mathrm{KBr}$.

Finally this experimental procedure was carried out identically but in the absence of $t$ BuOK, which did not yield any C-O cleavage compound.

Study of the low temperature $\mathrm{C}-\mathrm{O}$ cleavage in $\left[\mathrm{Fe}^{\mathrm{II}} \mathrm{Cp}\left(\eta^{6}-p \cdot \mathrm{CH}_{3} \mathrm{C}_{6} \mathrm{H}_{4} \mathrm{OCH}_{2} \mathrm{Ph}\right]\left[\mathrm{PF}_{6}\right]\right.$ by $\boldsymbol{t}$-BuOK in THF in the presence of allyl bromide. $\left[\mathrm{Fe}^{\mathrm{II}} \mathrm{Cp}\left(\eta^{6}-p \cdot \mathrm{CH}_{3} \mathrm{C}_{6} \mathrm{H}_{4} \mathrm{OCH}_{2} \mathrm{Ph}\right]\left[\mathrm{PF}_{6}\right](0.534\right.$ $\mathrm{g}, 1 \mathrm{mmol})$ and $t$-BuOK $(0.123 \mathrm{~g}, 1.1 \mathrm{mmol})$ and allyl bromide $(0.121 \mathrm{~g} ; 1 \mathrm{mmol})$ were introduced in a flamed Schlenk tube and deaerated, then $10 \mathrm{~mL}$ THF was added at $-50^{\circ} \mathrm{C}$, and the reaction medium was allowed to slowly warm up (in 3hrs) to room temperature, nd stirred stirred for one day at this temperature. Then, it was colled down again to $-50^{\circ} \mathrm{C}$, and $t$ $\operatorname{BuOK}(0.123 \mathrm{~g}, 1.1 \mathrm{mmol})$ and allyl bromide (0.121 g; $1 \mathrm{mmol})$ were added in $10 \mathrm{~mL}$ THF, and the reaction mixture was allowed to slowly warm up to room temperature. This operaration was repeated once more. Then, the mixture was allowed to warm up to room temperature, and the solvent was removed under vacuum. The residue was extracted with $10 \mathrm{~mL}$ ether after adition of $10 \mathrm{~mL}$ aq. $\mathrm{HCl}$, the organic layer was dried over $\mathrm{Na}_{2} \mathrm{SO}_{4}$, and filtered and submitted to gas chromatograpy on a Hewlett Packard 5890 chromatograph equipped with a Restek Rtxr-1 (fused silica) 30 m-long column. The commercial (Aldrich) standard ether $\mathrm{PhCH}_{2} \mathrm{Ot}$-Bu was synthesized $^{8}$ and used to check and quantify the formation of this ether in the reaction, which gave a $60 \%$ yield. The other ether formed in this reaction, p. $\mathrm{C}\left(\mathrm{CH}_{2} \mathrm{CH}=\mathrm{CH}_{2}\right)_{3} \mathrm{C}_{6} \mathrm{H}_{4} \mathrm{OCH}_{2} \mathrm{CH}=\mathrm{CH}_{2}, \mathbf{9}$, resulting from decomplexation was detected in low

amount (10\%) in the ${ }^{1} \mathrm{H}$ NMR spectrum. The aqueous phase was treated with $1 \mathrm{~mL}$ aq. $\mathrm{HPF}_{6}$ and extracted as indicated previously to give a $60 \%$ yield of the complex $\left[\mathrm{FeCp}\left\{\eta^{6}-p . \mathrm{C}\left(\mathrm{CH}_{2} \mathrm{CHCH}_{2}\right)_{3} \mathrm{C}_{6} \mathrm{H}_{4} \mathrm{OCH}_{2} \mathrm{CHCH}_{2}\right\}\right]\left[\mathrm{PF}_{6}\right], \mathbf{6}$ (see the characterizations above).

\section{Acknowledgments}

Financial support from the Institut Universitaire de France, the CNRS and the University Bordeaux I is gratefully acknowledged.

\section{References}

1. (a) Tchoubar, B. Les Mécanismes Réactionels en Chimie Organique, Dunod: Paris, 1960. (b) Lowry, T. H.; Richardson, K. H. Mechanisms and Theory in Organic Chemistry, $2^{\text {nd }}$ Edn., Harper and Row: New York, 1981.

2. Ions and Ion Pairs in Organic Reactions, Szwarc, M. Ed., Wiley: New York, 1972.

3. Loupy, A.; Tchoubar, B.; Astruc, D. Chem. Rev. 1992, 92, 1141.

4. Reichardt, C. Solvent Effects in Organic Chemistry, $2^{\text {nd }}$ Edn., VCH: Weinheim, 1988. 
5. (a) Russell, G. A.; Janzen, E. G.; Becker, H.; Smentowski, F. J. Am. Chem. Soc. 1962, 84, 2652. (b) Schriesheim, A.; Rowe, C. A. J. Am. Chem. Soc. 1962, 84, 3160.

6. Wallace, T. J.; Hoffmann, J. E.; Schriesheim, A. A. J. Am. Chem. Soc. 1963, 85, 2739.

7. Pearson, D. E.; Buehler, C. A. Chem. Rev. 1974, 74, 45.

8. DiBiase, S. A.; Gokel, G. W. J. Org. Chem. 1978, 43, 447.

9. Moulines, F.; Astruc, D. Angew. Chem. Int. Ed. 1988, 27, 1347.

10. Moulines, F.; Gloaguen, B.; Astruc, D. Angew. Chem. Int. Ed. 1992, 104, 452.

11. Astruc, D. Acc. Chem. Res. 2000, 33, 287.

12. Sartor, V.; Djakovitch, L.; Fillaut, J. L.; Moulines, F.; Neveu, F.; Marvaud, V.; Guittard, J.; Blais, J.-C.; Astruc, D. J. Am. Chem. Soc. 1999, 121, 2929.

13. Ruiz, J.; Lafuente, G.; Marcen, S.; Ornelas, C.; Lazare, S.; Cloutet, E.; Blais, J.-C.; Astruc, D. J. Am. Chem. Soc., 2003, 125, 7250.

14. Moulines, F.; Djakovitch, L.; Delville, M.-H.; Robert, F.; Gouzerh, P.; Astruc, D. J. Chem. Soc., Chem. Commun. 1995, 463.

15. de Gennes, P.-G. ; Hervet, H. J. Phys. Lett. 1983, 44, L 351.

16. Rosokha, S. V.; Kochi, J. K. In Modern Arene Chemistry, Astruc, D. Ed., Wiley-VCH: Weinheim, 2002, p. 435-478.

17. Helling, J. F. ; Hendrickson, W. A. J. Organomet. Chem. 1979, $168,87$.

18. Jursic, B. J. Chem. Res. 1989, 284.; Dehmlow, E. V.; Soufi, J.; Kessler, M. J. Chem. Res. 1990, 228.

19. Ruiz, J.; Lacoste, M; Astruc, D. J. Am. Chem. Soc. 1990, 112, 5471.

20. Narayana, C.; Padmanabhan, S.; Kabalka, G. W. Tetrahedron Lett. 1990, 31, 6977; Jursic, B. J. Chem. Res. 1989, 284; Dehmlov, E. V.; Soufi, J. Kesslere, M. J. Chem. Res. 1990, 228.

21. Staude, E.; Patrat, F. In The Chemistry of the Ether Linkage, Patai, S. Ed., Wiley: New York, 1967, p. 46-49 and refs. cited therein; Maercker, A. Angew. Chem. Int. Ed. 1987, 26, 972 and refs. cited therein.

22. Buncel, E.; Dust, J. M.; Jonczyk, A.; Manderville, R. A.; Onyido, L. J. Am. Chem. Soc. 1992, 114, 5610.

23. Astruc, D.; Nlate, S.; Ruiz, J. In Modern Arene Chemistry, Astruc, D. Ed., Wiley-VCH: Weinheim, 2002, pp 400-434.

24. Renard, C.; Rose, E.; Gagliardini, V.; Rose-Munch, F. Coord. Chem. Rev. 1998, 178, 249.

25. For a recent review of $\mathrm{CpFe}^{+}$activation of arenes, see: Abd-El-Aziz, A.; Bernardin, S. Coord. Chem. Rev. 2000, 203, 219.

26. Lewis, G. N. Valence and the Structure of Atoms and Molecules, The Chemical Catalog Company: New York, 1923, pp 141-142. 